Research Paper: Pathology

\title{
Dendritic cell-derived VEGF-A plays a role in inflammatory angiogenesis of human secondary lymphoid organs and is driven by the coordinated activation of multiple transcription factors
}

\author{
Valentina Salvi ${ }^{1}$, William Vermi ${ }^{1}$, Veronica Gianello ${ }^{1}$, Silvia Lonardi ${ }^{1}$, Vincenzo \\ Gagliostro ${ }^{1}$, Antonella Naldini ${ }^{3}$, Silvano Sozzani ${ }^{1,2, *}$ and Daniela Bosisio ${ }^{1, *}$ \\ ${ }^{1}$ Department of Molecular and Translational Medicine, University of Brescia, Brescia, Italy \\ 2 Humanitas Clinical and Research Centre, Rozzano, Italy \\ ${ }^{3}$ Department of Molecular and Developmental Medicine, University of Siena, Siena, Italy \\ * These authors have contributed equally to this work \\ Correspondence to:Silvano Sozzani, email: silvano.sozzani@unibs.it \\ Keywords: PAMPs, DAMPs, draining lymph node, CDla+ interdigitating DCs, CDlc+ DCs, Pathology Section \\ Received: March 17, 2016 \\ Accepted: May 20, 2016 \\ Published: May 31, 2016
}

\section{ABSTRACT}

Lymph node expansion during inflammation is essential to establish immune responses and relies on the development of blood and lymph vessels. Previous work in mice has shown that this process depends on the presence of VEGF-A produced by B cells, macrophages and stromal cells. In humans, however, the cell types and the mechanisms regulating the intranodal production of VEGF-A remain elusive. Here we show that $\mathrm{CD}^{11 \mathrm{C}^{+}}$cells represent the main VEGF-A-producing cell population in human reactive secondary lymphoid organs. In addition we find that three transcription factors, namely CREB, HIF-1a and STAT3, regulate the expression of VEGF-A in inflamed DCs. Both HIF-1a and STAT3 are activated by inflammatory agonists. Conversely, CREB phosphorylation represents the critical contribution of endogenous or exogenous $\mathrm{PGE}_{2}$. Taken together, these results propose a crucial role for DCs in lymph node inflammatory angiogenesis and identify novel potential cellular and molecular targets to limit inflammation in chronic diseases and tumors.

\section{INTRODUCTION}

VEGF-A is a potent pro-angiogenic mediator typically released under hypoxic conditions, but is also a hallmark of inflammation [1-3]. The regulation of VEGF-A secretion by hypoxia has been thoroughly characterized (reviewed in $[4,5]$ ). Far less is known about its regulation by pro-inflammatory stimuli, although transcription seems to play a predominant role [5]. The VEGF-A promoter spans more than $2 \mathrm{~kb}$ upstream of the transcription start site [6] and comprises many phylogenetically conserved binding sites for transcription factors such as HIF-1 $\alpha$, STAT3, CREB, nuclear receptors and Sp1 [5]. Among these, HIF-1 $\alpha$ is recognized as the master regulator of VEGF-A transcription, although it is now clear that other transcription factors are required to support its key function [7].

During inflammation, draining lymph nodes rapidly enlarge and increase in cellularity to foster the encounter between antigens and immune cells. Lymph node swelling is supported by a dramatic increase in blood vasculature to provide oxygen, nutrient and immune cell delivery [8] and by robust lymphangiogenesis that further enhances the possibilities of DC-T lymphocyte interactions [9] [10]. The mechanisms regulating the growth of blood and lymphatic vasculature in lymph nodes are not completely understood, but several studies point to a pivotal role for VEGF-A [11] [12] [13]. The intranodal source of VEGF-A has been investigated in the mouse system and comprises follicular B cells $[14,15], \mathrm{CD}_{11 \mathrm{~b}^{+}}$macrophages $[16$, 17] and reticular stromal cells [18]. Also CD11 $\mathrm{c}^{+}$DCs were suggested to have an indirect role in the increase of intranodal VEGF-A [13]. In humans, the cellular source of VEGF-A in inflamed lymph nodes remains completely elusive [19].

DCs are antigen presenting cells located at the interface between innate and adaptive immunity. DCs express a vast repertoire of pattern recognition receptors 
and the binding of pathogen- and damage-associated molecular patterns (PAMPs and DAMPs) activates a complex pro-inflammatory program that contributes to the local inflammatory response [20]. After antigen uptake in peripheral tissues, DCs travel via afferent lymphatics to the draining lymph nodes where they activate antigenspecific T lymphocytes [21].

We have previously reported that human monocytederived DCs represent an important source of biologically active VEGF-A ${ }_{165}$ and VEGF-A ${ }_{121}$ [22]. This work investigates the ability of DCs to produce VEGF-A in human activated lymph nodes and characterizes the molecular mechanisms responsible for VEGF-A transcription under inflammatory conditions.

\section{RESULTS}

\section{CD11 $^{+}$cells produce VEGF-A in human inflamed secondary lymphoid organs}

Staining of reactive tonsils and lymph nodes, including tumor-draining lymph nodes, with an antiVEGF-A antibody revealed a strong intracytoplasmic granular reactivity surrounding $\mathrm{CD} 31^{+}$high endothelial venules (HEVs) (Figure 1A). These VEGF-A ${ }^{+}$cells represented a fraction of $\mathrm{CD} 11 \mathrm{c}^{+}$cells in both lymph nodes (Figure 1B) and tonsils (Figure 1C), whereas pDCs, $\mathrm{B}$ and $\mathrm{T}$ lymphocytes were negative (Supplemental Figure

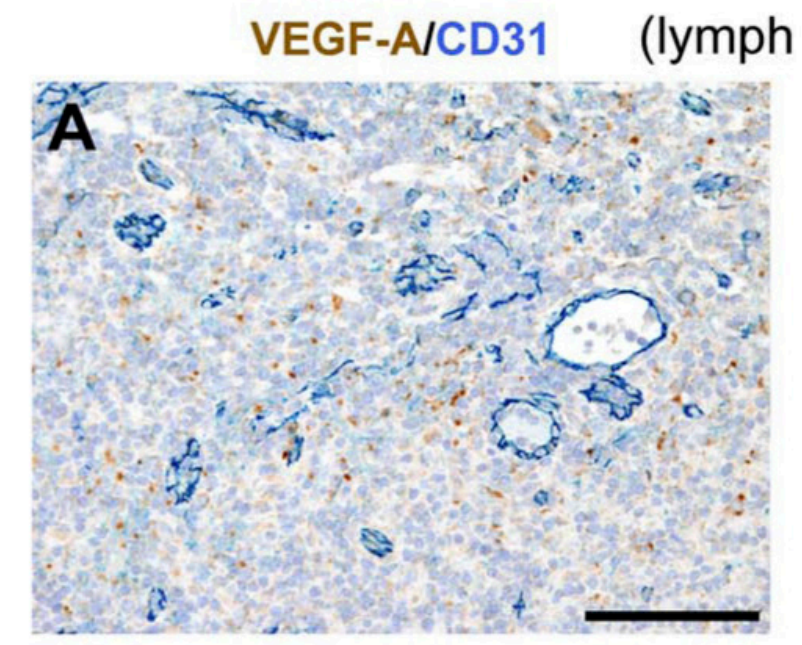

node) VEGF-A/CD11c
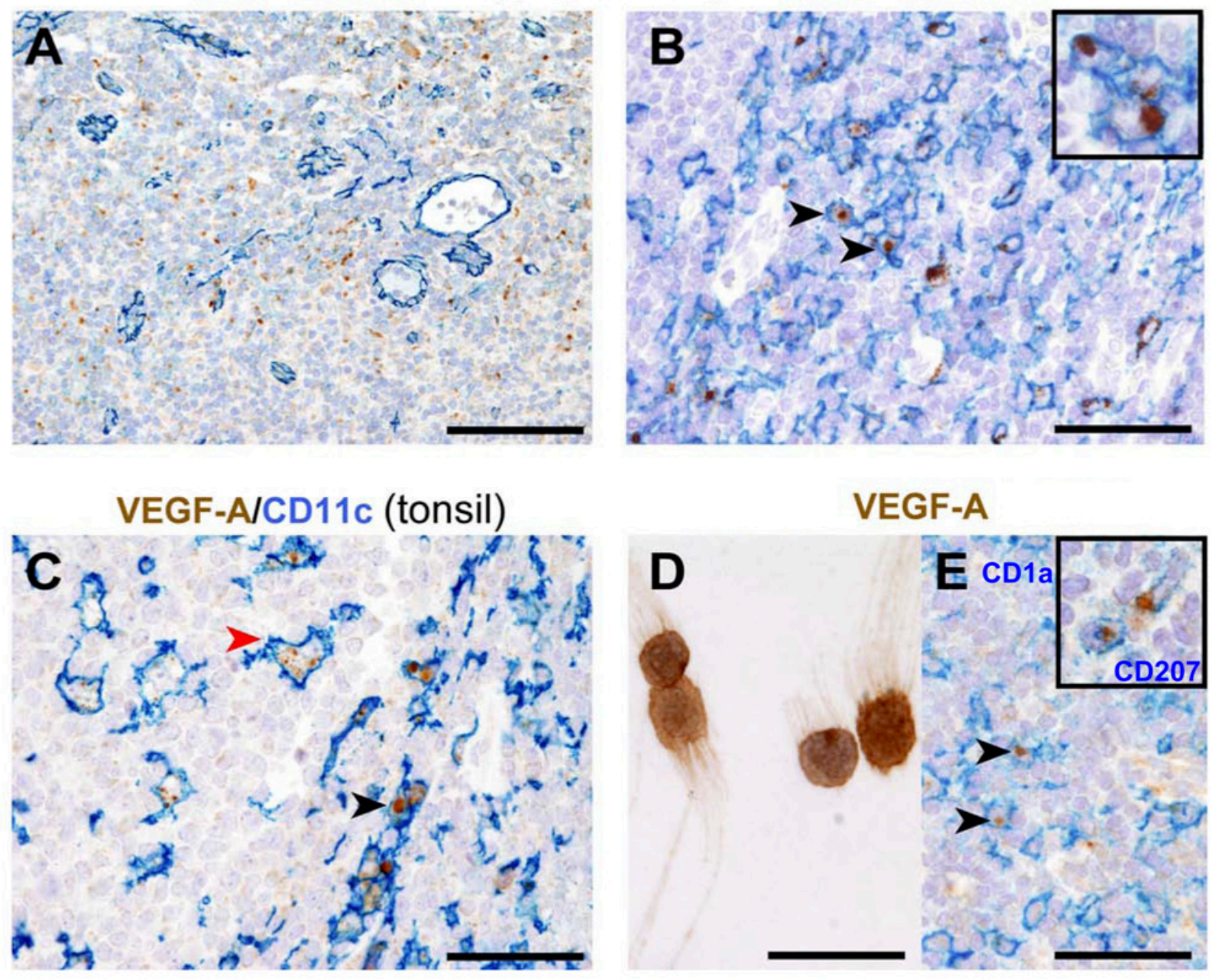

Figure 1: Distribution and phenotype of VEGF-A-producing cells in human reactive lymphoid tissues. A. In reactive lymph nodes, VEGF-A ${ }^{+}$cells surround $\mathrm{CD} 31^{+} \mathrm{HEVs}$ and B. co-express CD11c. C. In tonsils, strong cytoplasmic signal for VEGF-A is observed in CD11 $\mathrm{c}^{+}$cells in the interfollicular area (red arrow head) and CD11c+ germinal centre macrophages (black arrow head). D. Cytospin preparation of $\mathrm{CD} 1 \mathrm{c}^{+} \mathrm{DCs}$ sorted from tonsils shows VEGF-A-reactivity. E. In dermatopathic lymphadenitis, strong cytoplasmic VEGF-A is clearly detected in $\mathrm{CD}_{1 \mathrm{a}}{ }^{+}$and $\mathrm{CD} 207^{+}$(inset) interdigitating DCs. Sections are from FFPE reactive lymph nodes (A., B., E.) and tonsil (C). Stainings are indicated by labels. Representative double positive cells in each panel are indicated by arrow heads and detailed at a high power view insets. Sections are counterstained with Meyer's haematoxylin. Original magnifications: 200X (A., scale bar 100 $\mu$ m), 400X (B., C., E. scale bar $50 \mu \mathrm{m}), 600 X$ (D. and insets, scale bar $33 \mu \mathrm{m}$ ). 
1A, B and C). CD11 $\mathrm{c}^{+}$cells comprise both macrophages and myeloid DCs (mDCs), the latter being identified as $\mathrm{CD} 1 \mathrm{c}^{+}$. Since an anti-CD1c antibody working on formalin-fixed tissue sections is currently not available, the expression of VEGF-A by mDCs was confirmed in $\mathrm{CD} 1 \mathrm{c}^{+} \mathrm{mDCs}$ freshly purified from human tonsils (Figure 1D). Of note, as reported in previous studies, $\mathrm{CD} 1 \mathrm{c}^{+}$ cells represent the majority of $\mathrm{HLADR}^{+} \mathrm{CD} 11 \mathrm{c}^{+}$cells in reactive tonsils and lymph nodes (data not shown) [23, 24]. In addition to mDCs, VEGF-A reactivity was detected in $\mathrm{CD}_{1} \mathrm{a}^{+}$and $\mathrm{CD} 207^{+}$interdigitating DCs (Figure $1 \mathrm{E}$ and inset, respectively and in some $\mathrm{CD}_{163^{+}}$macrophages (Supplemental Figure 1D). In reactive tonsils, a minor fraction of M-DC8/DD1 ${ }^{+}$slanDCs costained for VEGF-A (Supplemental Figure 1E).

Collectively, these data indicate that myeloid DC subsets, interdigitating DCs of Langerhans cell derivation and macrophages represent a major source of VEGF-A in human inflamed secondary lymphoid organs.

\section{The release of VEGF-A induced by pro- inflammatory stimuli depends on the presence of PGE $_{2}$}

The ability of DCs to produce VEGF-A in response to different pro-inflammatory mediators was further investigated in vitro. Monocyte-derived DCs were stimulated with Toll Like Receptor-(TLR) ligands (Figure 2A), or whole bacteria (Staphilococcus aureus, Escherichia coli), C-type lectin ligands ( $\beta$-glucan, Curdlan and Candida albicans), pro-inflammatory cytokines (IL$1 \beta$ and TNF- $\alpha$ ) and necrotic cell-associated DAMPs (Figure 2B). Among these, only the ligands for TLR4 and TLR7-8, necrotic cell-associated DAMPs and, although at a low extent, $\beta$-glucan induced the release of VEGF-A. On the other hand, all stimuli became active in the presence of $\mathrm{PGE}_{2}$, the predominant eicosanoid produced in inflamed tissues and growing tumors [25]. Of note, $\mathrm{PGE}_{2}$ by itself did not induce VEGF-A (Figure 2A and 2B). According to the results obtained in tissue section, similar inductions were also obtained with in vitro differentiated Langerhans cells (Figure 2C) and primary mDCs (Figure 2D). Also, blood purified $\mathrm{pDCs}$ did not produce VEGF-A under basal conditions or when stimulated with TLR7- or TLR9ligands either in the presence or absence of $\mathrm{PGE}_{2}$ (Figure 2D).

Since LPS induces $\mathrm{PGE}_{2}$ synthesis [26], a role for endogenous $\mathrm{PGE}_{2}$ in inflammatory VEGF-A production was postulated. In accordance with this hypothesis, we found a clear correspondence between the capability to induce endogenous $\mathrm{PGE}_{2}$ and VEGF-A production (Figure 3A). Furthermore, the production of both mediators was ihibited by U0126, PD98059, SB203580 and BAY11-7082 (inhibitors of mitogen-activated protein kinase kinases, extracellular-signal-regulated kinase 1/2
(ERK1/2), MAPK p38 and NF- $\mathrm{BB}$ respectively), but not by the JNK inhibitor II (Figure 3B), suggesting the regulation by a common signalling pathways. Similar results were obtained with R848-stimulated DCs (data not shown). The role of endogenous $\mathrm{PGE}_{2}$ in VEGF-A secretion was further substantiated by two experimental approaches. First, by using specific inhibitors for two enzymes located upstream of $\mathrm{PGE}_{2}$ production, namely phospholipase $\mathrm{A}_{2}\left(\mathrm{PLA}_{2}\right)$ and COXs. Figure $3 \mathrm{C}$ shows that AACOF3 (a calcium-dependent PLA inhibitor), as well as indomethacin (a pan-COX-1/2 inhibitor), inhibited in a concentration-dependent manner VEGF-A production in LPS-stimulated DCs. As expected, both inhibitors also abolished the release of endogenous $\mathrm{PGE}_{2}$ (data not shown). We found that DCs express basal levels of Prostaglandin E receptor 2 and $4\left(\mathrm{EP}_{2}\right.$ and $\left.\mathrm{EP}_{4}\right)$ that are not modulated by LPS stimulation (Supplemental Figure 2A). These receptors are functional and mediate $\mathrm{DC}$ response to $\mathrm{PGE}_{2}$, because Butaprost (an $\mathrm{EP}_{2}$ agonist) and Misoprostol (a promiscuous $\mathrm{EP}_{2-4}$ agonist) recapitulated $\mathrm{PGE}_{2}$ effects in LPS-stimulated DCs (Supplemental Figure 2B). Thus, as a second approach, cell activation by autocrine $\mathrm{PGE}_{2}$ was blocked by the use of specific inhibitors of $\mathrm{EP}_{2}$ and $\mathrm{EP}_{4}$. Figure 3C shows that AH 6809+GW 627368X $\left(\mathrm{EP}_{2}\right.$ and $\mathrm{EP}_{4}$ antagonists, respectively) decreased VEGF-A production in a concentration-dependent manner.

Therefore, the ability of TLR-ligands to induce VEGF-A secretion directly correlates with the ability to activate $\mathrm{PGE}_{2}$ synthesis. This autocrine mechanism is supported by in vivo observations documenting the colocalization of anti-VEGF-A and anti-PGE 2 immunoreactivity in $\mathrm{CD} 11 \mathrm{c}^{+}$cells (Figure 3D).

\section{Inflammatory VEGF-A transcription requires the coordinated activation of multiple transcription factors}

These results prompted us to investigate the molecular mechanisms involved in the combined activation of DCs by TLR ligands and $\mathrm{PGE}_{2}$. Studies were focused on the combination Poly I:C+PGE ${ }_{2}$ as the paradigm of a positive interaction of two agonists that are by themself inactive in VEGF-A production, while LPS was selected as the prototypic active agonist. The induction of VEGF-A mRNA was largely dependent on the activation of gene transcription, as shown by the use of the RNA polymerase II (RNApolII) inhibitor 5,6-Dichloro$1-\beta$-D-ribofuranosylbenzimidazole (DRB), which dosedependently decreased the peak levels of VEGF-A mRNA (Figure 4A) and by RNApolII recruitment to the VEGF-A promoter by chromatin immunoprecipitation (ChIP) (Figure 4B).

Since $\mathrm{PGE}_{2}$ by itself does not induce VEGF-A production, it is likely to contribute to the activation of a transcription factor that is crucial, but not sufficient 

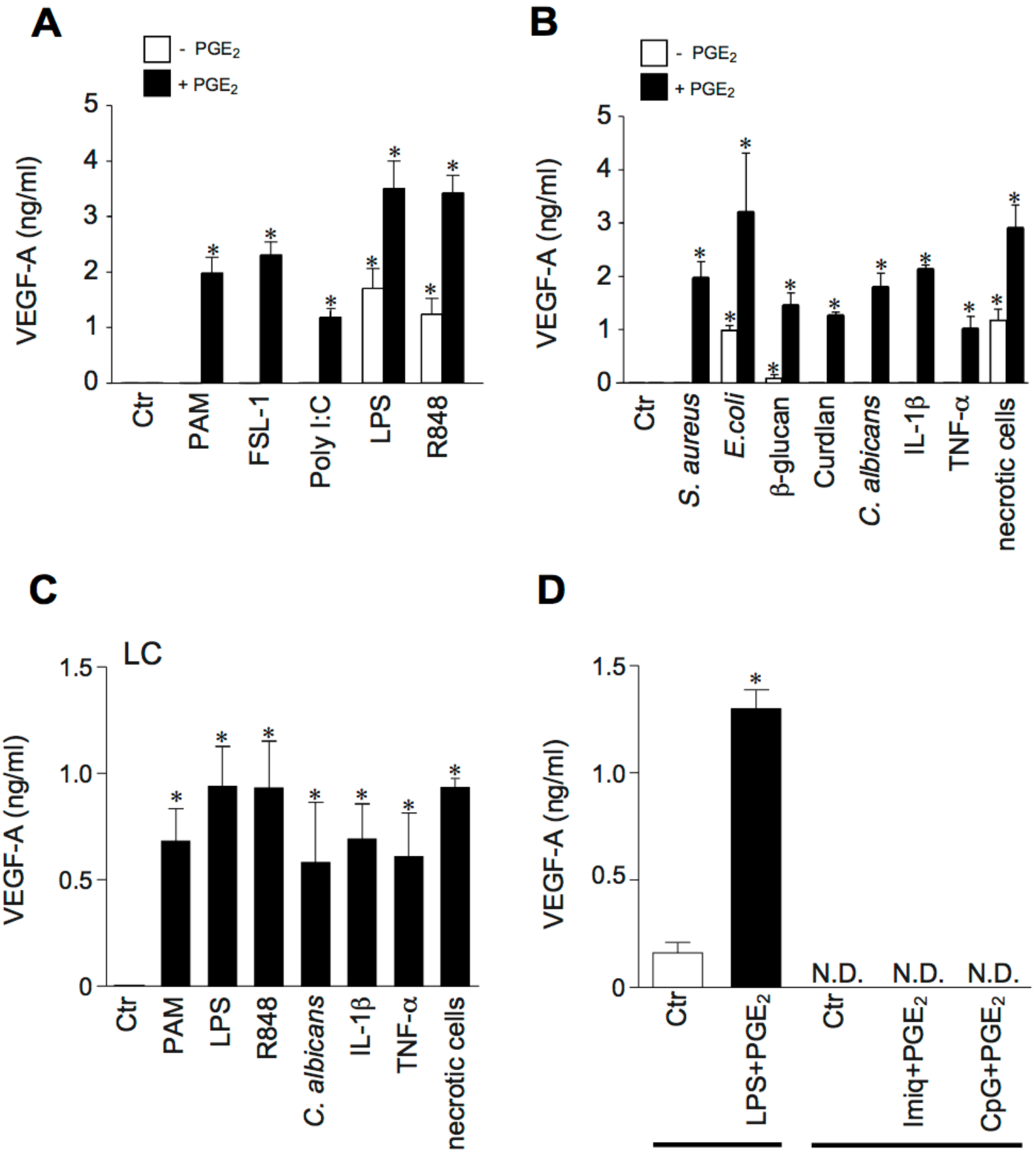

D

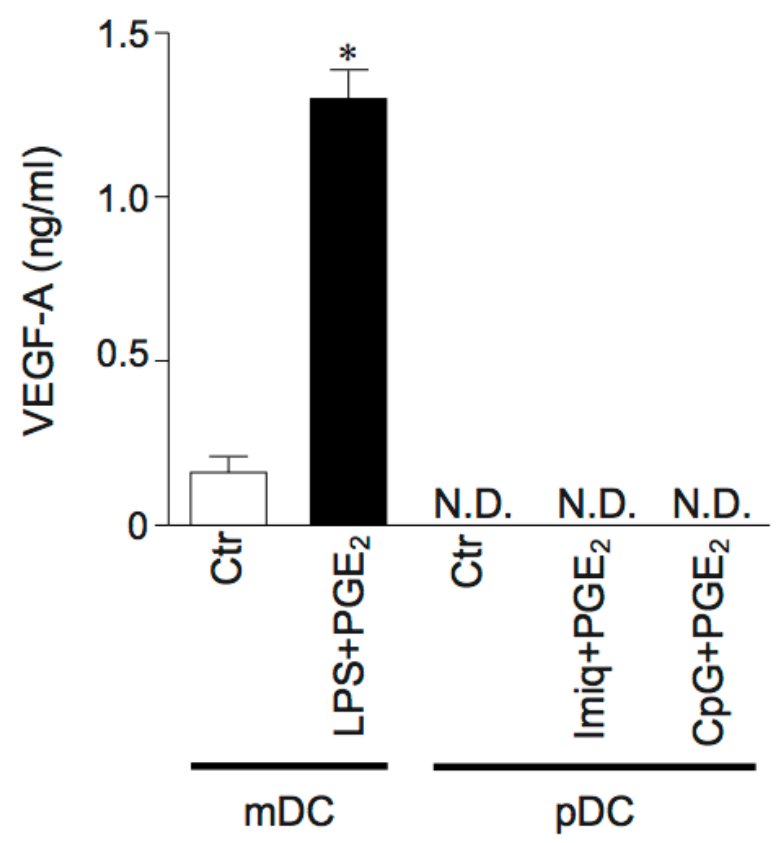

Figure 2: Human myeloid DCs produce VEGF-A in response to a variety of pro-inflammatory stimuli, provided PGE $^{2}$ is present in the microenvironment. A., B. DCs were stimulated for 24 hours with TLR-ligands PAM $_{3} \mathrm{CSK}_{4}(\mathrm{TLR} 1 / 2,100 \mathrm{ng} / \mathrm{ml})$, FSL-1 (TLR2/6, $100 \mathrm{ng} / \mathrm{ml}$ ), Poly I:C (TLR3, $25 \mu \mathrm{g} / \mathrm{ml}$ ), LPS (TLR4, $100 \mathrm{ng} / \mathrm{ml}$ ) and R848 (TLR7 and TLR8, $5 \mu \mathrm{g} / \mathrm{ml}$ ), Heat-killed S.aureus (specific for TLR2; 1:10 DC/bacteria ratio), E. coli (specific for TLR4; 1:10 DC/bacteria ratio), $\beta$-glucan (10 $\mu \mathrm{g} / \mathrm{ml})$, Curdlan (10 $\mu \mathrm{g} / \mathrm{ml})$, heat-killed C.albicans (specific for C-type lectins; 1:10 DC/fungi ratio), IL-1 $\beta(20 \mathrm{ng} / \mathrm{ml})$, TNF- $\alpha(20 \mathrm{ng} / \mathrm{ml})$, and necrotic cells $\left(1: 2 \mathrm{DC} /\right.$ necrotic cells ratio) in the presence or absence of $\operatorname{PGE}_{2}(10 \mu \mathrm{M})$. VEGF-A production was evaluated in cell-free supernatants by ELISA. Data are expressed as mean $+\operatorname{SEM}(n=4) ; * p<0.05$ by one-way ANOVA with Dunnet's post hoc test. C. Langerhans cells (LCs) were stimulated for 24 hours with PAM $_{3} \mathrm{CSK}_{4}(100 \mathrm{ng} / \mathrm{ml})$, LPS $(100 \mathrm{ng} / \mathrm{ml}), \mathrm{R} 848(5 \mu \mathrm{g} / \mathrm{ml})$, heat-killed C. albicans (1:10 DC/fungi ratio), IL-1 $\beta(20 \mathrm{ng} / \mathrm{ml})$, TNF- $\alpha(20 \mathrm{ng} / \mathrm{ml})$, and necrotic cells (1:2 DC/necrotic cells ratio) in the presence of $10 \mu \mathrm{M} \mathrm{PGE}$. VEGF-A production was evaluated by ELISA. Data are expressed as mean $+\operatorname{SEM}(n=3) .{ }^{*} p<0.05$ by one-way ANOVA with Dunnet's post hoc test D. Blood purified $\mathrm{mDCs}$ and $\mathrm{pDCs}$ were stimulated as indicated for 24 hours and VEGF-A levels were analyzed by ELISA. Data are expressed as mean $+\operatorname{SEM}(n=3) ; * p<0.05$ by Student's $t$ test; N.D. $=$ Not Detectable. 
per se, for the inflammatory production of VEGF-A. HIF-1 $\alpha$, STAT3 and CREB were selected for further analysis among the transcription factors able to bind the VEGF-A promoter [5] and known to be activated by TLRs and $\mathrm{PGE}_{2}$. Poly I:C and LPS, but not PGE , induced the nuclear accumulation of HIF-1 $\alpha$ as well as the phosphorylation and nuclear translocation of STAT3
(Figure $4 \mathrm{C}$, upper panels). By contrast, $\mathrm{PGE}_{2}$ induced the rapid phosphorylation of CREB (Figure 4C, lower panels). Of note LPS, the only tested agonist with the ability to induce VEGF-A directly, also induced the phosphorylation of CREB, suggesting that only the concomitant presence of these three transcription factors can promote the activation of VEGF-A transcription. According to this hypothesis,
A
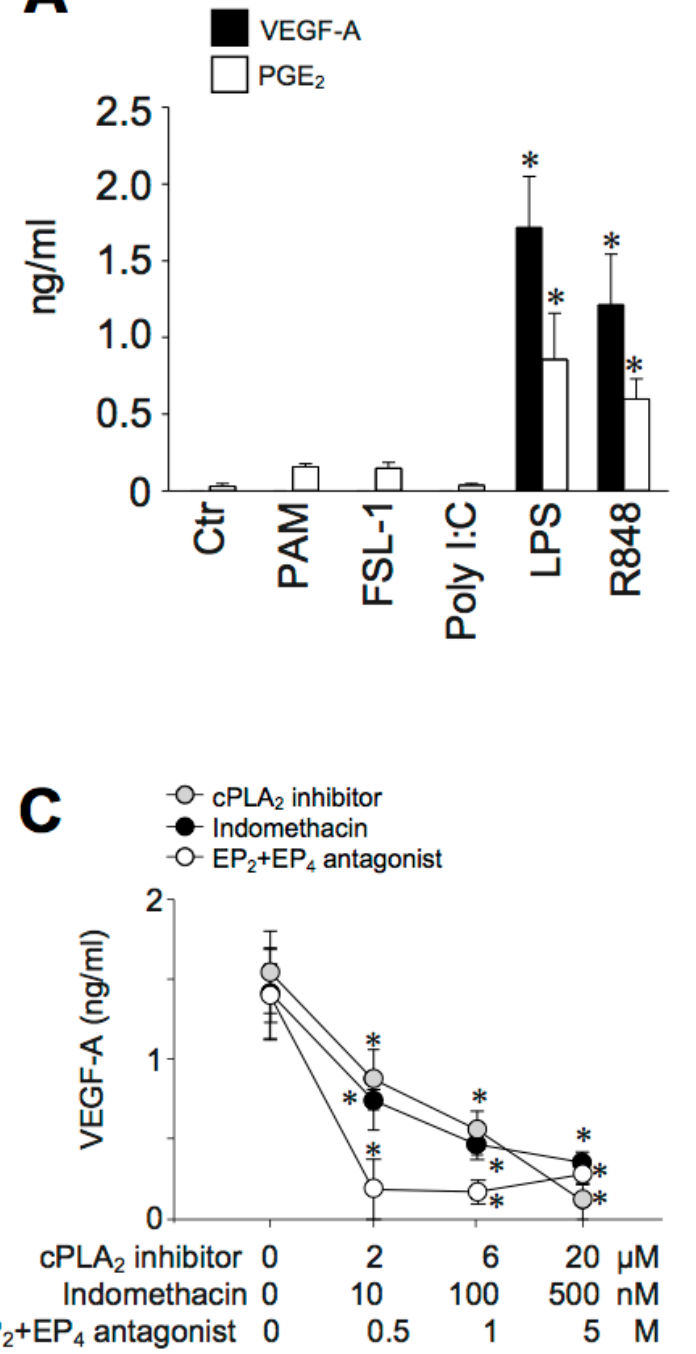

B

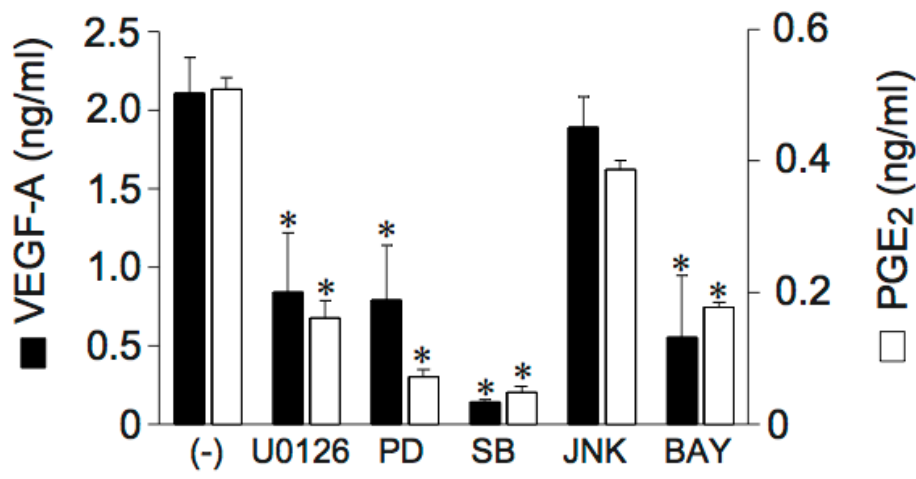

D

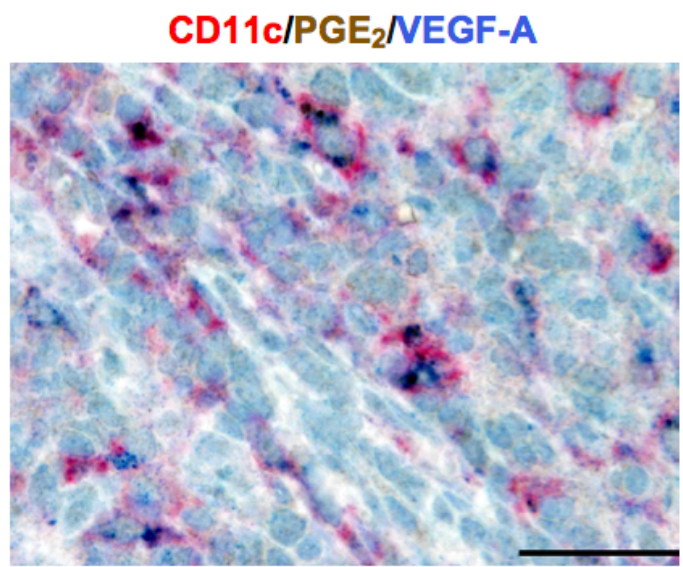

Figure 3: TLR-4-dependent expression of VEGF-A depends on endogenous PGE, production. A. DCs were stimulated with PAM $_{3} \mathrm{CSK}_{4}(100 \mathrm{ng} / \mathrm{ml})$, FSL-1 $(100 \mathrm{ng} / \mathrm{ml})$, Poly I:C $(25 \mu \mathrm{g} / \mathrm{ml})$, LPS (100 ng/ml) and R848 (5 $\left.\mu \mathrm{g} / \mathrm{ml}\right)$ for 24 hours. The production of VEGF-A and PGE $_{2}$ was evaluated in cell-free supernatants by ELISA or EIA, respectively. Results are expressed as mean + SEM ( $n$ $=4) ;{ }^{*} p<0.05$ by one-way ANOVA with Dunnet's post hoc test. B. DCs were pre-treated for 1 hour with U0126 (1 $\mu$ M), PD98059 (PD, $1 \mu \mathrm{M})$, SB203580 (SB, $1 \mu \mathrm{M})$, JNK Inhibitor II (JNK, $1 \mu \mathrm{M})$, BAY-11-7082 (BAY, $1 \mu \mathrm{M})$ and then stimulated with LPS (100 ng/ml) for 24 hours. VEGF-A and $\mathrm{PGE}_{2}$ production was evaluated by ELISA or EIA, respectively. Results are expressed as mean + SEM $(n=3) ; * p$ $<0.05$ by one-way ANOVA with Dunnet's post hoc test. C. DCs were pre-treated for 1 hour with increasing concentrations of AACOF3 (cPLA $\mathrm{A}_{2}$ inhibitor, grey circles), indomethacin (a non-selective COX-1/COX-2 inhibitor, black circles) or AH 6809+GW 627368X (EP 2 and $\mathrm{EP}_{4}$ antagonist respectively, open circles) and then stimulated with LPS. After 24 hours, supernatants were collected and the production of VEGF-A evaluated by ELISA. Data are expressed as mean $+\operatorname{SEM}(n=3) ;{ }^{*} p<0.05$ by one-way ANOVA with Dunnet's post hoc test. D. In reactive lymph nodes, a fraction of CD11 ${ }^{+}$cells costains for VEGF-A and PGE. Sections are counterstained with Meyer's haematoxylin. Original magnification: 600X (scale bar $33 \mu \mathrm{m}$ ). 
A

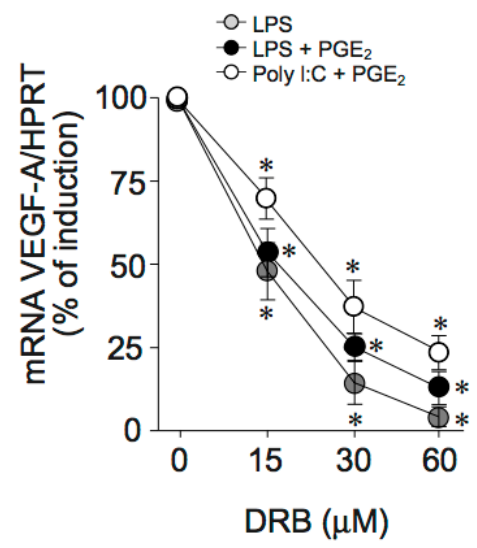

D
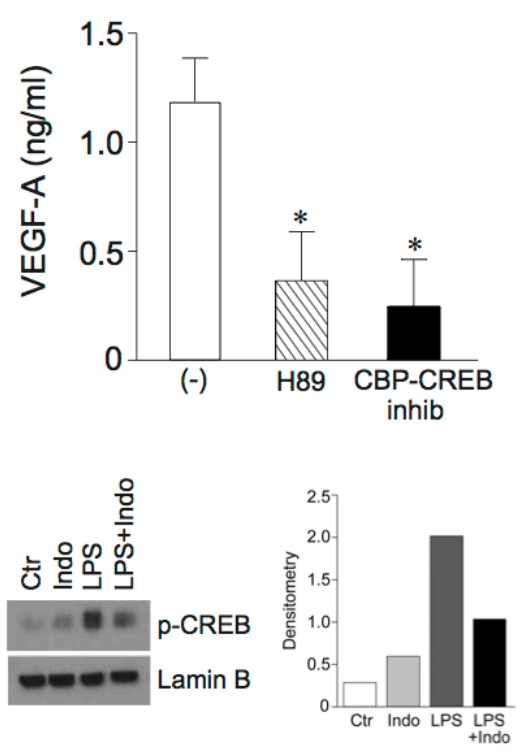

B

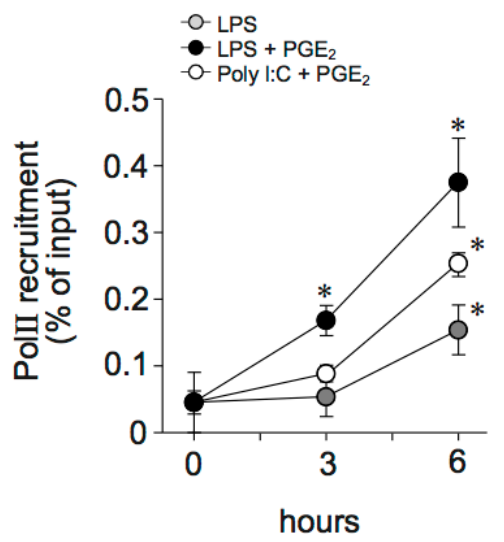

C

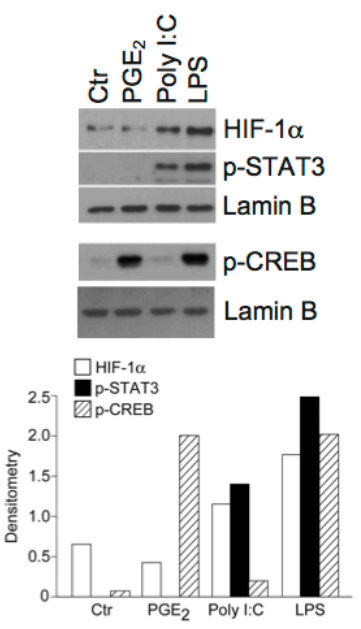

E

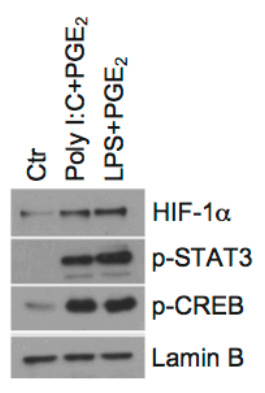

$\mathbf{F}$

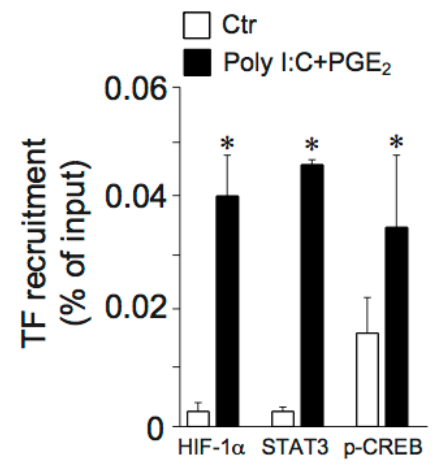

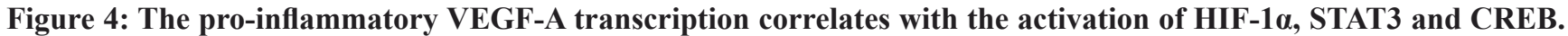
A. DCs were pre-treated with increasing concentrations of RNApolII inhibitor DRB for 30 minutes and then stimulated with LPS (6 hours), LPS $+\mathrm{PGE}_{2}$ or Poly I:C+PGE $(3$ hours). VEGF-A mRNA levels were evaluated by real-time PCR. Data are presented as mean $+\operatorname{SEM}(n=3)$ of percentage of induction $(100 \%$ indicates peak mRNA levels for each individual stimulus); $* p<0.05$ by one-way ANOVA with Dunnet's post hoc test. B. DCs were stimulated with LPS, LPS+PGE 2 or Poly I:C+PGE for the indicated time-points. Sonicated nuclear fractions were subjected to ChIP with anti-RNApolII (PolII) antibody and analyzed by RT-PCR. Data are shown as the immunoprecipitated percentage of input DNA and are expressed as mean $+\operatorname{SEM}(n=3) ; * p<0.05$ compared with respective controls by one-way ANOVA with Dunnet's post hoc test. C., E. DCs were stimulated with $10 \mu \mathrm{M}$ PGE, $25 \mu \mathrm{g} / \mathrm{ml}$ Poly I:C and $100 \mathrm{ng} / \mathrm{ml}$ LPS for 6 hours (C., upper panels) or 30 minutes (C., lower panels) or Poly I:C+PGE 2 or LPS $+\mathrm{PGE}_{2}$ for 3 hours (E) and blotted against HIF-1 $\alpha$, phospho-STAT3 or phospho-CREB. Lamin B represents the loading control for nuclear proteins. One representative fluorogram out of three and its densitometric analysis are shown. The time points shown in the figure represent the peak intensity of kinetic stimulations of 30 minutes, 1, 3, 6 and 8 hours. One representative experiment out of 3 is shown. D. (upper panel) DCs were pre-treated for 1 hour with 5 $\mu \mathrm{M} H 89$ (PKA inhibitor, striped bar) or $3 \mu \mathrm{M}$ CBP-CREB interaction inhibitor (black bar) and stimulated with LPS for 24 hours. VEGF-A production was evaluated by ELISA. Results are expressed as mean + SEM $(n=3) ;{ }^{*} p<0.05$ by one-way ANOVA with Dunnet's post hoc test. (D., lower panel) DCs were pre-treated for 30 minutes with $100 \mathrm{nM}$ indomethacin and then stimulated with LPS. Nuclear extracts were blotted against phospho-CREB. Lamin B represents the loading control for nuclear proteins. One representative fluorogram out of three and its densitometric analysis are shown. F. Nuclear fractions of DCs stimulated with Poly I:C+PGE for 3 hours were subjected to chromatin immunoprecipitation with antibodies directed against HIF-1 $\alpha$, phospho-CREB and STAT3. Data are shown as percentage of immunoprecipitated DNA and are expressed as mean $+\operatorname{SEM}(n=3) ; * p<0.05$ by Student's $t$ test. 
both a specific CREB inhibitor and H89, an inhibitor of the CREB-phosphorylating enzyme PKA, strongly reduced the secretion of VEGF-A in LPS-stimulated DCs (Figure 4D, upper panel). Also, indomethacin reduced the LPS-dependent phosphorylation of CREB, thus demonstrating that endogenous $\mathrm{PGE}_{2}$ is responsible for
CREB phosphorylation (Figure 4D, lower panel). Of note, the combined stimulation of DCs with Poly I:C+PGE induced the concomitant nuclear translocation of all transcription factors (Figure 4E) and their recruitment to the VEGF-A promoter (Figure 4F). Similar results were obtained in LPS $+\mathrm{PGE}_{2}$-stimulated DCs (Figure 4E and
A
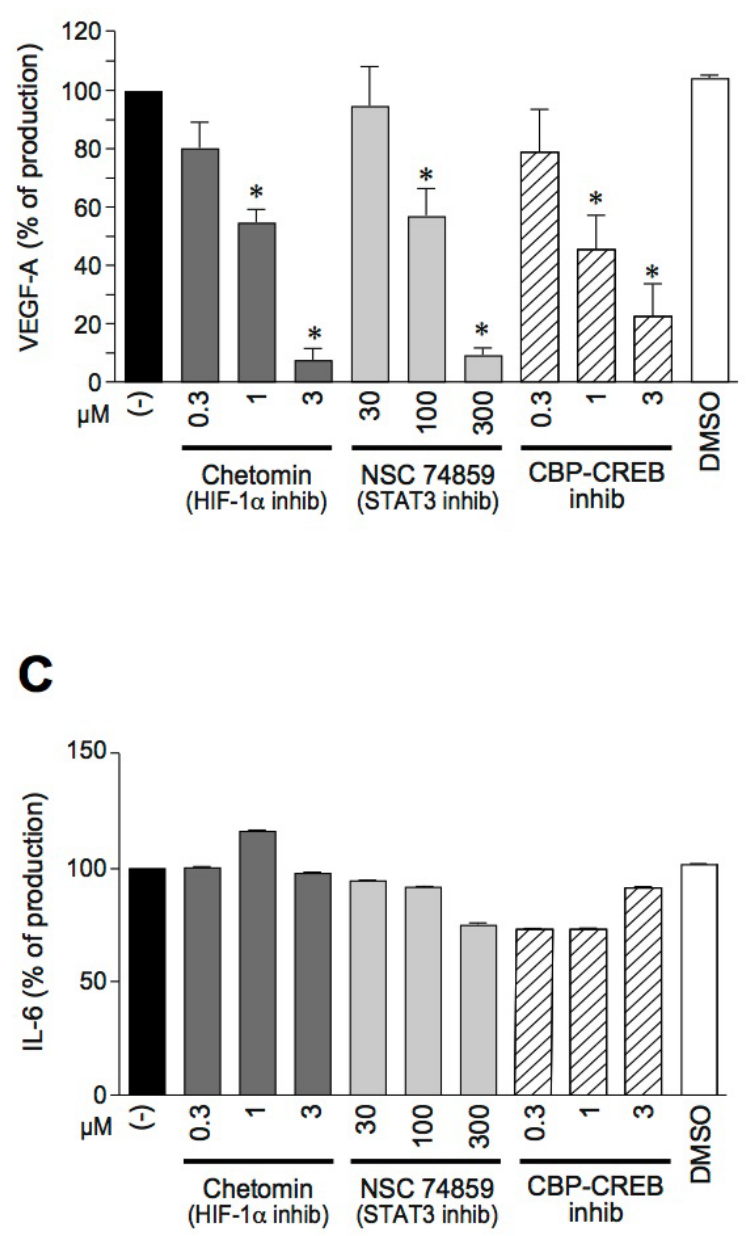

B
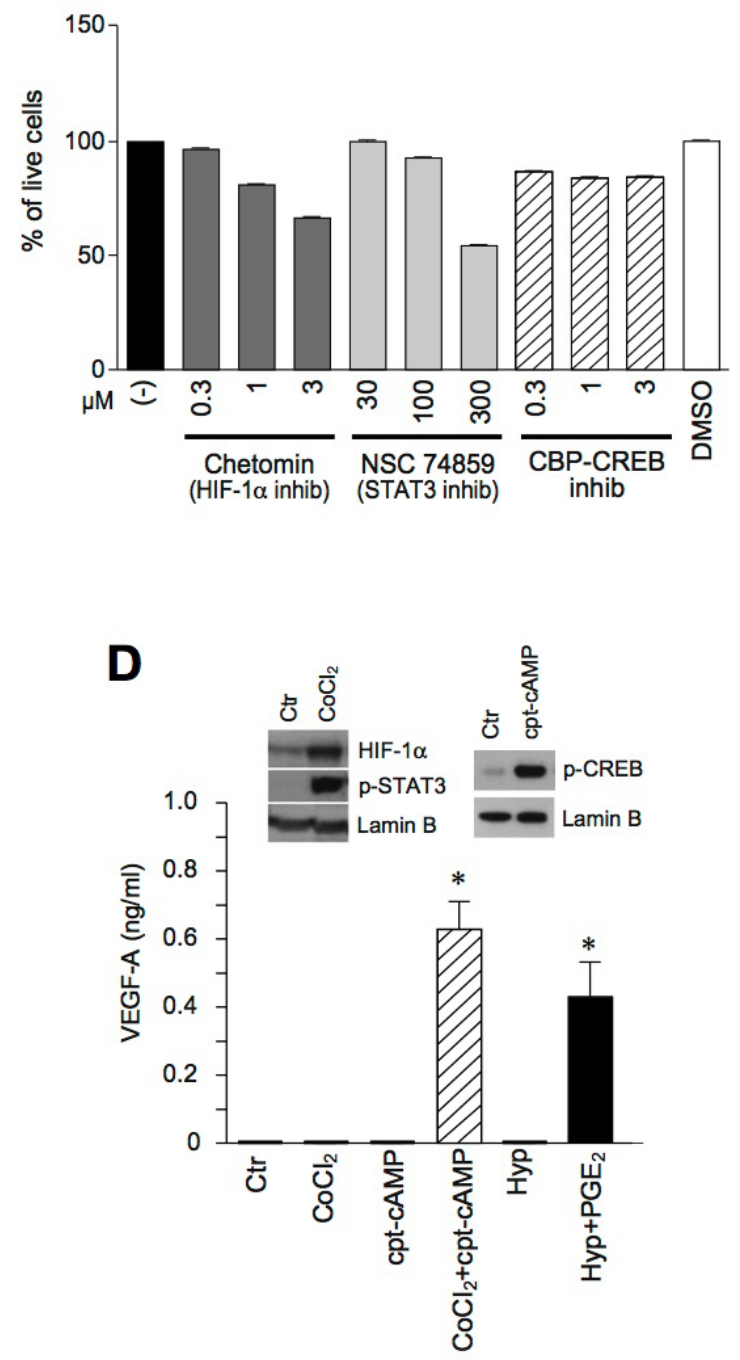

Figure 5: The pro-inflammatory secretion of VEGF-A requires the concomitant activation of HIF-1 $\alpha$, STAT3 and CREB. A.-C. DCs were pre-treated for 1 hour with Chetomin, NSC 74859 or CBP-CREB inhibitor and stimulated with Poly I:C+PGE for 24 hours. The release of VEGF-A (A) or IL-6 (C) was evaluated by ELISA. Cell viability was evaluated by Propidium Iodide staining (B). D. DCs were stimulated with $400 \mu \mathrm{M} \mathrm{CoCl}_{2}, 25 \mu \mathrm{M}$ cpt-cAMP alone or in combination and in hypoxic conditions (Hyp) in the presence or absence of $10 \mu \mathrm{M} \mathrm{PGE}_{2}$ for 24 hours. The production of VEGF-A was evaluated by ELISA in cell free supernatants. Results are expressed as mean $+\operatorname{SEM}(n=3){ }^{*} p<0.05$ compared to respective controls by Student's $t$ test or one-way ANOVA with Dunnet's post hoc test as appropriate. (D., left inset) DCs were stimulated with $400 \mu \mathrm{M} \mathrm{CoCl}_{2}$ for 4 hours or (D., right inset) with $25 \mu \mathrm{M}$ cpt-cAMP for 30 minutes and blotted against HIF-1 $\alpha$, phospho-STAT3 or phospho-CREB. Lamin B represents the loading control for nuclear proteins. 
Supplemental Figure 3A).

The requirement of these three transcription factors for VEGF-A production was further confirmed by the use of specific inhibitors. Figure $5 \mathrm{~A}$ shows that Chetomin (an inhibitor of the interaction of HIF-1 $\alpha$ with transcriptional co-activators p300 and CBP), NSC 74859 (a STAT3 inhibitor) and CBP-CREB (a CREB inhibitor) dose-dependently reduced the secretion of VEGF-A after Poly I:C $+\mathrm{PGE}_{2}$ stimulation. Although with the highest concentrations of the first two inhibitors a minor reduction in cell viability was observed at the end of 24 hour-stimulation (Figure 5B), the ability of the cells to release IL-6, an unrelated cytokine, was not affected (Figure 5C). These results strongly suggest that the inhibition of VEGF-A production was not due to the toxic effects of the inhibitors. Similar results were obtained in LPS+PGE 2 -stimulated DCs (Supplemental Figure 3B-3D). Finally, the involvement of multiple transcription factors in VEGF-A induction was further strengthened by the use of chemical activators. Figure 5D shows that, in human
DCs, $\mathrm{CoCl}_{2}$ (a drug activating HIF-1 $\alpha$ and STAT3, left inset [27]) or hypoxia, were by themselves inactive and induced VEGF-A only when combined with the CREBphosphorylating agonist (8-(4-Chlorophenylthio)-cAMP (cpt-cAMP), or $\mathrm{PGE}_{2}$.

These results indicate that the transcriptional activation of VEGF-A in inflamed DCs requires the concomitant activation of multiple transcription factors, namely CREB, HIF- $1 \alpha$ and STAT3, and that CREB phosphorylation represents the crucial contribution of $\mathrm{PGE}_{2}$ to TLR-dependent VEGF-A secretion.

\section{DISCUSSION}

Activated DCs produce large amounts of chemokines, cytokines and oxygen radicals and represent an important component of the inflammatory reaction [21]. In adults, angiogenesis occurs mostly under pathological conditions, including inflammation. Newly formed blood vessels provide nutrients to growing tissues and allow

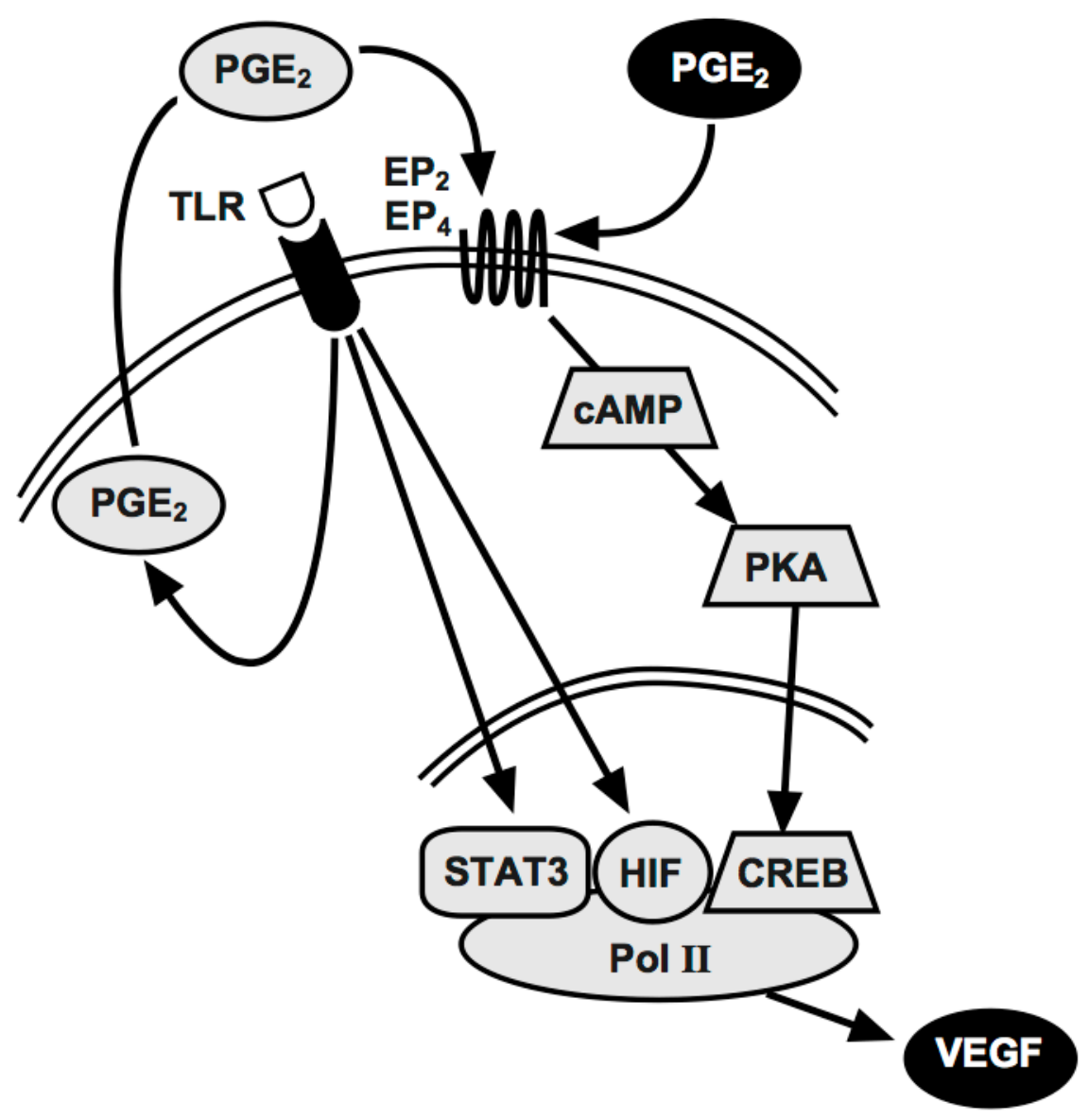

Figure 6: Proposed model for inflammatory VEGF-A production. The triggering of TLR4 (or TLR7-8) induces the release of endogenous $\mathrm{PGE}_{2}$ (grey circle) which acts autocrinally on $\mathrm{EP}_{2}$ and/or $\mathrm{EP}_{4}$ receptors inducing robust CREB phosphorylation. This, together with TLR-activated HIF-1 $\alpha$ and STAT3, finally induces VEGF-A transcription. For pattern recognition receptors that don't release PGE exogenous $\mathrm{PGE}_{2}$ (black circle) provides CREB phosphorylation. 
accumulation of immune cells, both in peripheral tissues and in secondary lymphoid organs [1]. In this study we have identified the nature of VEGF-A producing cells in sections of human reactive lymph nodes and tonsils. Specifically, double-immunohistochemistry shows that $\mathrm{CD} 1 \mathrm{c}^{+} \mathrm{mDC}$ and interdigitating DCs represent a major source of VEGF-A in inflamed secondary lymphoid organs. Interdigitating DCs originate from Langerhans cells migrated via lymphatics. On the other hand, $\mathrm{CD} \mathrm{c}^{+} \mathrm{mDCs}$, located in the extranodular compartments surrounding HEVs, likely migrated from the blood. Because of their different nodal location, each of these cell types may play a specific role in the neo-angiogenesis process of lymphatics sinuses and HEVs, respectively.

Our results from in vitro studies show that DCs can readily produce VEGF-A in response to a large variety of PAMPs and DAMPs if $\mathrm{PGE}_{2}$ is present in the local microenvironment, demonstrating a non-redundant role for $\mathrm{PGE}_{2}$ in VEGF-A production by DCs. This $\mathrm{PGE}_{2}$ may either be endogenously produced by DCs, or provided together with the stimuli (outlined in Figure 6). Despite $\mathrm{PGE}_{2}$ concentrations shown in Figure 2A and $2 \mathrm{~B}$ were higher than those released by DCs (Figure 3A), similar results were obtained with $\mathrm{PGE}_{2}$ concentrations resembling those autocrinally released $(0.01 \mu \mathrm{M}$, not shown). The presence of $\mathrm{CD} 11 \mathrm{c} / \mathrm{VEGF}-\mathrm{A} / \mathrm{PGE}_{2}$ positive cells in tissue sections supports the existence of an autocrine mechanism in vivo. In addition $\mathrm{PGE}_{2}$, which is abundantly produced by many cell types in inflamed tissues and lymph nodes $[25,11,12]$, may also act paracrinally to support VEGF-A production in the presence of PAMPs or DAMPs unable to induce $\mathrm{PGE}_{2}$ in $\mathrm{DCs}$. $\mathrm{PGE}_{2}$ regulates several $\mathrm{DC}$ functions including migration, edema formation and $\mathrm{T}$ cell polarization [25] [28] [29] [30]. This report further strengthen the importance of $\mathrm{PGE}_{2}$ in $\mathrm{DC}$ biology showing the crucial role of this prostenoid for VEGF-A production. Furthermore, this study provides an additional mechanism by which COX-2 may promote inflammatory and/or tumor angiogenesis [31].

From a mechanistic point of view, our data propose CREB phosphorylation as the crucial contribution of $\mathrm{PGE}_{2}$ to VEGF-A secretion, while TLRs are responsible for the activation of HIF-1 $\alpha$ and STAT3. The mechanisms of HIF$1 \alpha$ and STAT3 activation by TLRs remain unexplained. It was previously described in cancer cell lines that proinflammatory cytokines and TLR3-4 ligands induce HIF$1 \alpha$ accumulation under normoxic conditions [32-36], an effect often correlated with COX-2 activation. However, in DCs, HIF-1 $\alpha$ accumulation does not depend on COX-2 activation since it is detected also after the stimulation with Poly I:C. In addition, we found that COX inhibition could not prevent HIF-1 $\alpha$ accumulation in LPS-stimulated DCs (V.S., unpublished results). Based on these observations, we hypothesize that HIF-1 $\alpha$ accumulation may depend on a direct effect of TLR signalling, possibly mediated by ROS that were described to inhibit PHD enzymes and stabilize HIF-1 $\alpha$ protein [37]. The mechanisms of STAT3 activation are even more puzzling. A good candidate would be an autocrine loop involving IL-6, which is induced by several TLRs and is a well known VEGF-A inducer [5]. However, an IL-6R-blocking antibody did not inhibit the release of VEGF-A (V.S., unpublished results) in our system. Also, the production of VEGF-A was not affected by antibodies blocking the receptors for IL-10 and IFN-I (V.S., unpublished results), thus suggesting the involvement of a different mediator which remains elusive. Further work is granted to better characterize the mechanisms responsible for HIF-1 $\alpha$ and STAT3 activation in TLR-stimulated DCs.

The conclusion that, in DCs, three transcription factors (namely HIF-1 $\alpha$, STAT3 and CREB) are required to induce VEGF-A transcription (outlined in Figure 6) is supported by experiments performed with specific inhibitors and by the observation that agonists which fail to induce the activation of these transcription factors also fail to induce VEGF-A transcription, unless combined with exogenous $\mathrm{PGE}_{2}$. This is the case for TLR3 activation, which accumulates HIF-1 $\alpha$ and phospho-STAT3 but fails to induce CREB phosphorylation. Similarly, $\mathrm{CoCl}_{2}$, which accumulates HIF- $1 \alpha$ and phospho-STAT3, induces VEGF-A only when combined with CREB-activating drug cpt-cAMP. These latter findings suggest that the presence of three transcription factors is crucial not only in pro-inflammatory, but also in hypoxic conditions. In the past, seminal work postulated the need for a multiprotein complex, including HIF-1 $\alpha$ and an "adjacent transcription factor" to regulate the transcription of hypoxic genes $[38,39]$. In line with this, it was recently proposed that STAT3 may cooperatively activate HIF-1 $\alpha$-target genes by increasing the recruitment of the coactivators CBP and p300 [7, 27, 40]. Our results further support these findings showing the need for three transcription factors for the inflammatory production of VEGF-A.

An unresolved question is whether HIF-1 $\alpha$, STAT3 and CREB activate VEGF-A transcription dependently or independently from each other, i.e. if they form a protein complex (or enhanceosome) in human DCs. Even in the absence of direct evidence from co-occupancy experiments, several data strongly support this hypothesis. First, the three transcription factors can be detected on the same promoter region, encompassing functional HIF and STAT3 sites less than 150 bp apart one from the other. This region is devoid of a characterized CRE site, but a nearby (less than $200 \mathrm{bp}$ ) functional AP-1 site [5] may bind CREB because of core consensus sequence similarities [41]. Alternatively, the binding of CREB to the VEGF-A promoter may be indirect, i.e. mediated by coactivators as previously proposed [42]. Finally, we show that the inhibition of each single transcription factor completely flattens the secretion of VEGF-A. This suggests the existence of a protein complex encompassing the three transcription factors, which cannot be assembled in the 
lack of one member, thus failing to recruit co-activators and to activate transcription.

In conclusion, this study shows that, in inflammatory conditions, human DCs can produce conspicuous amounts of VEGF-A, in vitro and in vivo. Our data also show that in inflamed lymph nodes DCs represent one of the few cell types contributing VEGF-A production. This finding makes DCs a new potential therapeutic target to limit lymph node vascular expansion in chronic- and tumor-associated inflammation. Furthermore, the formal definition of the enhanceosome composition might allow to specifically target DC-derived VEGF-A preserving the physiological angiogenesis as well as the global activation of transcription factors mastering key physiological processes. Altogether, this study further expands our knowledge on the plasticity of DCs and on their complex role in the regulation of innate immune responses.

\section{MATERIALS AND METHODS}

\section{Immunohistochemistry}

Formalin-fixed paraffin-embedded human tissues were retrieved from the archive of the Department of Pathology (Spedali Civili di Brescia, Brescia, Italy). Anti-VEGF-A polyclonal antibody (1:500, Thermo Scientific, CA) was applied to $4-\mu \mathrm{m}$ thick tissue sections, after appropriate antigen retrieval (microwave oven $3 \times 5$ minutes 750W in EDTA buffer, $\mathrm{pH} 8.0$ ); the reaction was revealed using Novolink Polymer (Leica Microsystems, UK) followed by DAB. Anti-PGE 2 (polyclonal Rabbit, 1:700 over night, Biorbyt) was revealed using DakoEnvision+System-HRP Labelled Polymer AntiRabbit and DAB after antigen retrieval (thermostatic bath, TRIS-EDTA buffer, $\mathrm{pH}$ 9.0). Isotype control stains for both VEGF-A and $\mathrm{PGE}_{2}$ were performed and gave no reactivity. Characterization of VEGF-A positive cells was performed by double immunohistochemistry using antibodies to the following antigens: CD31 (mouse IgG1, clone 1A10, 1:50, Leica Microsystems), CD1a (mouse, clone 010, 1:50, Dako, Denmark), CD3 (rabbit, clone SP7, 1:100, Thermo Scientific), CD11c (mouse, clone 5D11, 1:50, Leica Microsystems), CD20 (mouse, clone L26, 1:250, Dako), CD163 (mouse, clone 10D6, 1:50, Thermo Scientific), CD207/Langerin (mouse, clone 12D6, 1:200, Vector Laboratories, CA) and CD303/BDCA2 (mouse, clone 124B3.13, 1:75, Dendritics, France) and M-DC8 (mouse, clone DD1, 1:70, kindly provided by K. Schäkel) and visualized using Mach 4 MR-AP (Biocare Medical, CA), followed by Ferangi Blue (Biocare Medical) as chromogen. Immunostained sections were photographed using the DP-70 Olympus digital camera mounted on the Olympus BX60 microscope.

\section{Cell preparation and culture}

Buffy coats were obtained through the courtesy of the Centro Trasfusionale, Spedali Civili, Brescia. Monocytes were purified from peripheral blood mononuclear cells (PBMC) by immunomagnetic separation using anti CD14-conjugated magnetic microbeads (Miltenyi Biotec, Bergisch Gladbach, Germany). Monocyte-derived DCs were differentiated as previously described [43]. Briefly, monocytes cultured for 6 days in tissue culture plates in RPMI 1640 (Gibco, Invitrogen, Carlsbad, CA, USA) supplemented with $10 \%$ heat-inactivated fetal calf serum (FCS, Lonza Group, Switzerland), 2 mM L-glutamine, antibiotics (Gibco) (completed RPMI medium), $50 \mathrm{ng} / \mathrm{ml}$ GM-CSF and $20 \mathrm{ng} / \mathrm{ml}$ IL-4 (ProSpec Technogene, Israel). To generate Langerhans cells, monocytes were cultured for 6 days in completed RPMI medium in the presence of $50 \mathrm{ng} / \mathrm{ml}$ GM-CSF, $10 \mathrm{ng} / \mathrm{ml} \mathrm{IL-4}$ and $10 \mathrm{ng} / \mathrm{ml} \mathrm{TGF}-\beta$ (Peprotech, London, U.K). Langerhans cell differentiation was controlled by monitoring Langerin and E-Cadherin expression. Myeloid DCs (mDCs) and plasmacytoid DCs (pDCs) were isolated using the corresponding Cell Isolation Kit (Miltenyi Biotec). pDCs were cultured in completed RPMI medium and 20 ng/ml IL-3 (ProSpec). Necrotic cells were obtained via four cycles of freezing and thawing. Hypoxia $\left(1 \% \mathrm{O}_{2}, 37^{\circ} \mathrm{C}\right)$ was performed in the InVivo 2400 hypoxic workstation (Ruskinn-Biotrace, UK).

\section{Cell stimulation}

DCs $\left(2 \times 10^{6}\right.$ cells $\left./ \mathrm{ml}\right)$ were stimulated with the following agonists: $100 \mathrm{ng} / \mathrm{ml} \mathrm{PAM}_{3} \mathrm{CSK}_{4}$, ligand for TLR1/2; $100 \mathrm{ng} / \mathrm{ml} \mathrm{FSL-1,} \mathrm{ligand} \mathrm{for} \mathrm{TLR2/6;} 25 \mu \mathrm{g} / \mathrm{ml}$ Poly I:C, ligand for TLR3; $100 \mathrm{ng} / \mathrm{ml}$ flagellin, ligand for TLR5 (Bacillus subtilis); $5 \mu \mathrm{g} / \mathrm{ml}$ imiquimod, ligand for TLR7; $5 \mu \mathrm{g} / \mathrm{ml} \mathrm{R848,} \mathrm{ligand} \mathrm{for} \mathrm{TLR7} \mathrm{and} \mathrm{TLR8} \mathrm{(from}$

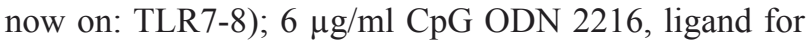
TLR9 (all from Invivogen, San Diego, California, USA); $100 \mathrm{ng} / \mathrm{ml}$ LPS, ligand for TLR4 (Escherichia coli 055:B5; Sigma-Aldrich, St. Louis, MO); $10 \mu \mathrm{g} / \mathrm{ml} \beta$-glucan from baker's yeast (Saccharomyces cervisiae) or Curdlan (from Alcaligenes faecalis), both ligands for dectin-1 (both from Sigma-Aldrich); 20 ng/ml IL-1 $\beta$ and TNF- $\alpha$ (Peprotech). Heat-killed Staphylococcus aureus, Escherichia coli and Candida albicans was purchased from Invivogen. Where indicated, $10 \mu \mathrm{M} \mathrm{PGE}_{2}, 25 \mu \mathrm{M}$ cpt-cAMP, $400 \mu \mathrm{M}$ Cobalt Chloride $\left(\mathrm{CoCl}_{2}\right)$ were added (all from Sigma-Aldrich). DRB (an inhibitor of RNApolII), Chetomin (HIF-1 $\alpha$ inhibitor), NSC 74859 (STAT3 inhibitor) were from Sigma-Aldrich; indomethacin (a non selective COX1 and COX-2 inhibitor), U0126 (a MEK1/2 inhibitor), PD98059 (an ERK1/2 inhibitor), SB203580 (a p38 MAPK inhibitor), JNK Inhibitor II (a JNK inhibitor), BAY11-7082 (a NF- $\mathrm{B}$ inhibitor), CBP-CREB interaction 
inhibitor were from Calbiochem (San Diego, CA); H89 (a PKA inhibitor), AH 6809 (an $\mathrm{EP}_{2}$ antagonist), GW 627368X (an $\mathrm{EP}_{4}$ antagonist), Butaprost (EP 2 agonist), Misoprostol $\left(\mathrm{EP}_{4}, \mathrm{EP}_{3}>\mathrm{EP}_{2}\right.$ agonist $)$ and Sulprostone $\left(\mathrm{EP}_{1} /\right.$ $\mathrm{EP}_{3}$ agonist) were from Cayman Chemical (Michigan, USA). AACOF3 (Arachidonyltrifluormethyl ketone, a cPLA $A_{2}$ inhibitor) was purchased from Biomol (Enzo Life Sciences, Farmingdale).

\section{Chromatin immunoprecipitation}

After stimulation, cells were fixed by adding directly to the medium 36\% formaldehyde (SigmaAldrich) to a final concentration of $1 \%$ for 7 minutes. The cross-linking reaction was stopped by adding Tris to a final concentration of $125 \mathrm{mM}$. After 10 minutes, ice-cold PBS was added and plates were transferred on ice, washed extensively with PBS, and scraped. After centrifugation, cells were lysed for 5 minutes in L1 buffer (50 mM Tris pH 8.0, 2 mM EDTA, 0.1\% Nonidet P-40 and $10 \%$ glycerol) supplemented with inhibitors (1 mM Na3VO4, $2 \mathrm{mM}$ DTT, $1 \mathrm{mM} \mathrm{NaF,} 1 \mathrm{mM}$ PMSF and Protease Inhibitors Cocktail, all reagents were purchased from Sigma-Aldrich). Nuclei were pelleted at $3000 \mathrm{rpm}$ in a cold microfuge and resuspended in L2 buffer $(50 \mathrm{mM}$ Tris $\mathrm{pH}$ 8.0, 1\% SDS and 5 mM EDTA) plus inhibitors. Chromatin was sheared by sonication ( $3 \times 20 \mathrm{~s}$ at $50 \%$ of the maximum potency), centrifuged to pellet debris, and diluted 10 times in dilution buffer $(50 \mathrm{mM}$ Tris pH 8.0, 0.5\% Nonidet P-40, $200 \mathrm{mM} \mathrm{NaCl}$ and $5 \mathrm{mM}$ EDTA). Extracts were precleared for 3 hours with a $50 \%$ suspension of salmon sperm-saturated protein A (ss protein A). Immunoprecipitations were carried out overnight at $4^{\circ} \mathrm{C}$ using $3 \mu \mathrm{g}$ of the following antibodies raised against RNApolII (N-20 sc-899, Santa Cruz Biotechnology, CA, USA), HIF-1 $\alpha$ (NB 10134, Novus Biologicals, CO, USA), STAT3 (C-20 sc-482, Santa Cruz Biotechnology) [44], pCREB $^{\text {Ser133 }}$ (Cat. 17-10131, Millipore; USA). Immune complexes were collected with protein $\mathrm{A}$ and washed three times (10 minutes each) with high salt buffer (washing buffer: $20 \mathrm{mM}$ Tris pH 8.0, 0.1\% SDS, 1\% Nonidet P-40, $2 \mathrm{mM}$ EDTA and $500 \mathrm{mM} \mathrm{NaCl}$ supplemented with $1 \mathrm{mM}$ PMSF) and three times with low salt buffer (1x Tris/ EDTA [TE]). Immune complexes were extracted in 1x TE containing $2 \% \mathrm{SDS}$, and protein-DNA cross-links were reverted by heating at $65^{\circ} \mathrm{C}$ overnight. DNA was then extracted with the QIAquick PCR purification kit (Qiagen, Crawley, UK) and $1 / 20$ of the immunoprecipitated DNA was used in each quantitative PCR reaction. Sequences of promoter-specific primers used were the following: VEGF-A -884 to detect transcription factor binding (forward: 5'-TGATGTCTGCAGGCCAGAT-3', reverse: 5'-CCACAGTGTGTCCCTCTGAC-3') and VEGF-A -291 to detect RNApolII recruitment (forward: 5'-GTCCGCACGTAACCTCACTT-3', reverse: 5'-CAGCCTGAAAATTACCCATCC-3'). In all experiments, $10 \%$ of the input chromatin was removed prior to addition of the antibodies and used to normalize the amount of immunoprecipitated DNA (specified in the text as "input" DNA).

\section{ELISA}

DCs were incubated for 24 hours with the indicated treatments. Cell-free supernatants were harvested and VEGF-A and IL-6 production was measured by ELISA assay (R\&D Systems, Minneapolis, MN, USA). PGE ${ }^{2}$ production was assessed by EIA kit (Cayman Chemical).

\section{SDS-PAGE and western blot}

Following the designated treatments, DCs were washed twice with PBS and lysed in L1 buffer with inhibitors to separate cytoplasmic proteins. Nuclear pellets were washed twice with L1 buffer with inhibitors and then lysed in Nonidet P-40 Lysis buffer (50 mM Tris-HCl, $\mathrm{pH}$ 8.0; $250 \mathrm{mM} \mathrm{NaCl} ; 1 \mathrm{mM}$ EDTA; 0.1\% Nonidet P-40 and $10 \%$ glycerol) with inhibitors. Equal amounts of extracts were analyzed through 8-12\% SDS-PAGE followed by Western blotting with antibodies against phospho-CREB (Cat. 9198, Cell Signalling), phospho-STAT3 (Cat. 9131, Cell Signalling), HIF-1 $\alpha$ (Cat. 610959, BD Bioscience), and Lamin B (C-20 sc-6216, Santa Cruz Biotechnology). Protein bands were detected with SuperSignal West Pico Chemiluminescent Substrate (Pierce, Rockford, USA). Densitometric analysis was performed using ImageJ (version 1.48) software package from National Institutes of Health. Immunoblots were scanned as JPEG images and the areas under the curves were measured for each band and quantified. Data were normalized based on Lamin B content.

\section{Real-time PCR}

RNA was extracted using TRIzol reagent (Invitrogen) according to the manufacturer's instructions. After RNA purification, samples were treated with DNAse to remove contaminating genomic DNA (DNaseI Amplification grade, Invitrogen). Reverse transcription was performed using random hexamers and MMLV RT (Invitrogen). Gene-specific primers used were as follows: hVEGF-A (forward: 5'-AGTGTGTGCCCACTGAGGA-3', reverse: 5'-GGTGAGGTTTGATCCGCATA-3'), hHPRT (forward: 5'-CCAGTAACAGGGGACATAAA-3', reverse: 5'-CACAATCAAGACATTCTTTCCAGT-3'). The SsoAdvanced Universal SYBR Green Supermix (Bio-Rad Laboratories Inc., Hercules, CA, USA) for quantitative real-time PCR was used according to the manufacturer's instructions. Reactions were run in triplicate on a StepOne 
Plus Real-Time PCR System (Applied Biosystems) and the generated products analyzed by the StepOne Plus Software (Version 2.3, Applied Biosystems). Gene expression was normalized based on HPRT mRNA content.

\section{FACS analysis}

DCs were treated with $100 \mathrm{ng} / \mathrm{ml}$ LPS for 24 hours. At the end of the incubation, cells were permeabilized using the Cytofix/Cytoperm kit (BD Bioscience, San Diego, CA) and stained with antibodies against $\mathrm{EP}_{2}$ and $\mathrm{EP}_{4}$ receptors (Cayman Chemical) or with the isotype control for 30 minutes, washed with PBS (Gibco) and incubated with anti-rabbit Alexa-488 (Invitrogen). Samples were read on a PAS (Partec GmbH, Muenster, Germany) and analysed with FlowJo (Tree Star Inc, Ashland, USA). To assess cell viability, DCs were stained with Propidium Iodide (Invitrogen).

\section{Statistical analysis}

Statistical significance among the experimental groups was determined using paired Student's $t$ test or oneway ANOVA with Dunnet's post hoc test as appropriated (GraphPad Prism version 4.00 for Windows, GraphPad Software).

\section{ACKNOWLEDGMENTS}

We thank Drs. F. Calzetti and A. Micheletti for the preparation of CD1c ${ }^{+}$DCs from tonsils.

\section{CONFLICTS OF INTEREST}

The authors have declared that no conflict of interests exists.

\section{GRANT SUPPORT}

This work was supported by AIRC (Associazione Italiana Ricerca sul Cancro); Fondazione Berlucchi; MIUR (Ministero dell'Istruzione Università e Ricerca) and Fondazione Cariplo. V.S. was the recipient of a fellowship from FIRC (Fondazione Italiana Ricerca sul Cancro) and supported by New Opportunities and Ways towards ERC - NOW ERC grant (Project ID 2014-2256) from Cariplo Foundation and Regione Lombardia. V.Gi. was supported by the IAP (Interuniversity Attraction Poles) 7-40 program.

\section{Authors' contributions}

V.S., W.V., A.N., S.S. and D.B. conceived experiments. V.S., V.Gi., S.L. and V.Ga. performed experiments. V.S., W.V., V.Gi., S.L., V.Ga., S.S. and D.B. analysed and interpreted data. A.N., S.S. and D.B. wrote the manuscript. All authors contributed to the editing and reviewing of manuscript and artwork and approved the present version of the manuscript.

\section{REFERENCES}

1. Szade A, Grochot-Przeczek A, Florczyk U, Jozkowicz A and Dulak J. Cellular and molecular mechanisms of inflammation-induced angiogenesis. IUBMB life. 2015; 67:145-159.

2. Chung AS and Ferrara N. Developmental and pathological angiogenesis. Annual review of cell and developmental biology. 2011; 27:563-584.

3. Sica A, Melillo G and Varesio L. Hypoxia: a double-edged sword of immunity. Journal of molecular medicine (Berlin, Germany). 2011; 89:657-665.

4. Arcondeguy T, Lacazette E, Millevoi S, Prats H and Touriol C. VEGF-A mRNA processing, stability and translation: a paradigm for intricate regulation of gene expression at the post-transcriptional level. Nucleic Acids Res. 2013; 41:7997-8010.

5. Pages $G$ and Pouyssegur J. Transcriptional regulation of the Vascular Endothelial Growth Factor gene--a concert of activating factors. Cardiovasc Res. 2005; 65:564-573.

6. Buteau-Lozano H, Ancelin M, Lardeux B, Milanini J and Perrot-Applanat M. Transcriptional regulation of vascular endothelial growth factor by estradiol and tamoxifen in breast cancer cells: a complex interplay between estrogen receptors alpha and beta. Cancer Res. 2002; 62:4977-4984.

7. Pawlus MR, Wang L and Hu CJ. STAT3 and HIF1alpha cooperatively activate HIF1 target genes in MDA-MB-231 and RCC4 cells. Oncogene. 2014; 33:1670-1679.

8. Anderson ND, Anderson AO and Wyllie RG. Microvascular changes in lymph nodes draining skin allografts. The American journal of pathology. 1975; 81:131-160.

9. Kim H, Kataru RP and Koh GY. Regulation and implications of inflammatory lymphangiogenesis. Trends in immunology. 2012; 33:350-356.

10. Liao S and Ruddle NH. Synchrony of high endothelial venules and lymphatic vessels revealed by immunization. J Immunol. 2006; 177:3369-3379.

11. Foss HD, Araujo I, Demel G, Klotzbach H, Hummel M and Stein H. Expression of vascular endothelial growth factor in lymphomas and Castleman's disease. The Journal of pathology. 1997; 183:44-50.

12. Nishi J, Arimura K, Utsunomiya A, Yonezawa S, Kawakami K, Maeno N, Ijichi O, Ikarimoto N, Nakata M, Kitajima I, Fukushige T, Takamatsu H, Miyata K and Maruyama I. Expression of vascular endothelial growth factor in sera and lymph nodes of the plasma cell type of Castleman's disease. British journal of haematology. 1999; 104:482-485. 
13. Webster B, Ekland EH, Agle LM, Chyou S, Ruggieri R and Lu TT. Regulation of lymph node vascular growth by dendritic cells. The Journal of experimental medicine. 2006; 203:1903-1913.

14. Angeli V, Ginhoux F, Llodra J, Quemeneur L, Frenette PS, Skobe M, Jessberger R, Merad M and Randolph GJ. $\mathrm{B}$ cell-driven lymphangiogenesis in inflamed lymph nodes enhances dendritic cell mobilization. Immunity. 2006; 24:203-215.

15. Shrestha B, Hashiguchi T, Ito T, Miura N, Takenouchi K, Oyama Y, Kawahara K, Tancharoen S, Ki IY, Arimura N, Yoshinaga N, Noma S, Shrestha C, Nitanda T, Kitajima $\mathrm{S}$, Arimura K, et al. B cell-derived vascular endothelial growth factor A promotes lymphangiogenesis and high endothelial venule expansion in lymph nodes. J Immunol. 2010; 184:4819-4826.

16. Kataru RP, Jung K, Jang C, Yang H, Schwendener RA, Baik JE, Han SH, Alitalo K and Koh GY. Critical role of $\mathrm{CD} 11 \mathrm{~b}+$ macrophages and VEGF in inflammatory lymphangiogenesis, antigen clearance, and inflammation resolution. Blood. 2009; 113:5650-5659.

17. Kim KE, Koh YJ, Jeon BH, Jang C, Han J, Kataru RP, Schwendener RA, Kim JM and Koh GY. Role of CD11b+ macrophages in intraperitoneal lipopolysaccharide-induced aberrant lymphangiogenesis and lymphatic function in the diaphragm. The American journal of pathology. 2009; 175:1733-1745.

18. Chyou S, Ekland EH, Carpenter AC, Tzeng TC, Tian S, Michaud M, Madri JA and Lu TT. Fibroblast-type reticular stromal cells regulate the lymph node vasculature. J Immunol. 2008; 181:3887-3896.

19. Cella $M$ and Trinchieri G. A new VEGF connection between two old neighbors. Nature immunology. 2014; 15:8-9.

20. Merad M, Sathe P, Helft J, Miller J and Mortha A. The dendritic cell lineage: ontogeny and function of dendritic cells and their subsets in the steady state and the inflamed setting. Annual review of immunology. 2013; 31:563-604.

21. Sozzani S. Dendritic cell trafficking: more than just chemokines. Cytokine \& growth factor reviews. 2005; 16:581-592.

22. Riboldi E, Musso T, Moroni E, Urbinati C, Bernasconi S, Rusnati M, Adorini L, Presta M and Sozzani S. Cutting edge: proangiogenic properties of alternatively activated dendritic cells. J Immunol. 2005; 175:2788-2792.

23. Micheletti A, Finotti G, Calzetti F, Lonardi S, Zoratti E, Bugatti M, Stefini S, Vermi W and Cassatella MA. slan/MDC8+ cells constitute a distinct subset of dendritic cells in human tonsils. Oncotarget. 2016; 7:161-175. doi: 10.18632/ oncotarget.6660.

24. Segura E, Valladeau-Guilemond J, Donnadieu MH, SastreGarau X, Soumelis V and Amigorena S. Characterization of resident and migratory dendritic cells in human lymph nodes. The Journal of experimental medicine. 2012;
209:653-660.

25. Kalinski P. Regulation of immune responses by prostaglandin E2. J Immunol. 2012; 188:21-28.

26. Funk CD. Prostaglandins and leukotrienes: advances in eicosanoid biology. Science. 2001; 294:1871-1875.

27. Gray MJ, Zhang J, Ellis LM, Semenza GL, Evans DB, Watowich SS and Gallick GE. HIF-1alpha, STAT3, CBP/ p300 and Ref-1/APE are components of a transcriptional complex that regulates Src-dependent hypoxia-induced expression of VEGF in pancreatic and prostate carcinomas. Oncogene. 2005; 24:3110-3120.

28. Harizi H and Gualde N. The impact of eicosanoids on the crosstalk between innate and adaptive immunity: the key roles of dendritic cells. Tissue antigens. 2005; 65:507-514.

29. Randolph GJ, Sanchez-Schmitz G and Angeli V. Factors and signals that govern the migration of dendritic cells via lymphatics: recent advances. Springer seminars in immunopathology. 2005; 26:273-287.

30. Zanoni I, Ostuni R, Barresi S, Di Gioia M, Broggi A, Costa B, Marzi R and Granucci F. CD14 and NFAT mediate lipopolysaccharide-induced skin edema formation in mice. The Journal of clinical investigation. 2012; 122:1747-1757.

31. Gately S and Li WW. Multiple roles of COX-2 in tumor angiogenesis: a target for antiangiogenic therapy. Semin Oncol. 2004; 31:2-11.

32. Jung Y, Isaacs JS, Lee S, Trepel J, Liu ZG and Neckers L. Hypoxia-inducible factor induction by tumour necrosis factor in normoxic cells requires receptor-interacting protein-dependent nuclear factor kappa B activation. The Biochemical journal. 2003; 370:1011-1017.

33. Jung YJ, Isaacs JS, Lee S, Trepel J and Neckers L. IL-1betamediated up-regulation of HIF-1alpha via an NFkappaB/ COX-2 pathway identifies HIF-1 as a critical link between inflammation and oncogenesis. Faseb J. 2003; 17:21152117.

34. Stasinopoulos I, O'Brien DR and Bhujwalla ZM. Inflammation, but not hypoxia, mediated HIF-1alpha activation depends on COX-2. Cancer biology \& therapy. 2009; 8:31-35.

35. Paone A, Galli R, Gabellini C, Lukashev D, Starace D, Gorlach A, De Cesaris P, Ziparo E, Del Bufalo D, Sitkovsky MV, Filippini A and Riccioli A. Toll-like receptor 3 regulates angiogenesis and apoptosis in prostate cancer cell lines through hypoxia-inducible factor 1 alpha. Neoplasia. 2010; 12:539-549.

36. Spirig R, Djafarzadeh S, Regueira T, Shaw SG, von Garnier C, Takala J, Jakob SM, Rieben R and Lepper PM. Effects of TLR agonists on the hypoxia-regulated transcription factor HIF-1alpha and dendritic cell maturation under normoxic conditions. PloS one. 2010; 5:e0010983.

37. Brune B and Zhou J. The role of nitric oxide (NO) in stability regulation of hypoxia inducible factor-1alpha (HIF1alpha). Current medicinal chemistry. 2003; 10:845-855. 
38. Ebert BL and Bunn HF. Regulation of transcription by hypoxia requires a multiprotein complex that includes hypoxia-inducible factor 1 , an adjacent transcription factor, and p300/CREB binding protein. Molecular and cellular biology. 1998; 18:4089-4096.

39. Forsythe JA, Jiang BH, Iyer NV, Agani F, Leung SW, Koos RD and Semenza GL. Activation of vascular endothelial growth factor gene transcription by hypoxia-inducible factor 1. Molecular and cellular biology. 1996; 16:46044613.

40. Rathinavelu A, Narasimhan M and Muthumani P. A novel regulation of VEGF expression by HIF-1alpha and STAT3 in HDM2 transfected prostate cancer cells. Journal of cellular and molecular medicine. 2012; 16:1750-1757.

41. Lamph WW, Dwarki VJ, Ofir R, Montminy M and Verma IM. Negative and positive regulation by transcription factor cAMP response element-binding protein is modulated by phosphorylation. Proceedings of the National Academy of Sciences of the United States of America. 1990; 87:43204324.
42. Wu D, Zhau HE, Huang WC, Iqbal S, Habib FK, Sartor O, Cvitanovic L, Marshall FF, Xu Z and Chung LW. cAMPresponsive element-binding protein regulates vascular endothelial growth factor expression: implication in human prostate cancer bone metastasis. Oncogene. 2007; 26:50705077.

43. Salvi V, Scutera S, Rossi S, Zucca M, Alessandria M, Greco D, Bosisio D, Sozzani S and Musso T. Dual regulation of osteopontin production by TLR stimulation in dendritic cells. Journal of leukocyte biology. 2013; 94:147-158.

44. Tamassia N, Castellucci M, Rossato M, Gasperini S, Bosisio D, Giacomelli M, Badolato R, Cassatella MA and Bazzoni F. Uncovering an IL-10-dependent NF-kappaB recruitment to the IL-1ra promoter that is impaired in STAT3 functionally defective patients. Faseb J. 2010; 24:1365-1375. 